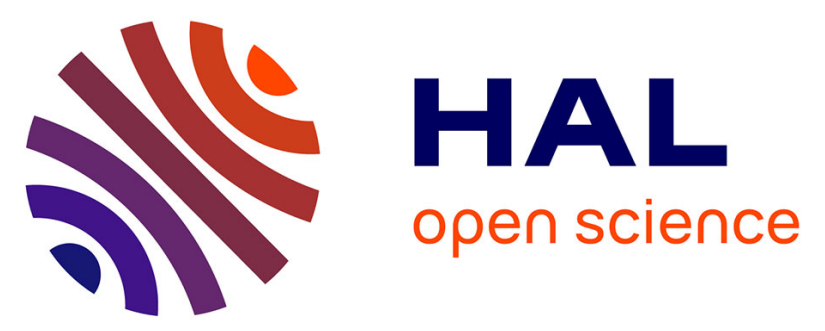

\title{
Childhood adversity trajectories and PTSD in young adulthood: A nationwide Danish register-based cohort study of more than one million individuals
}

Fabienne El-Khoury, Andreas Rieckmann, Jessica Bengtsson, Maria Melchior, Naja Hulvej Rod

\section{- To cite this version:}

Fabienne El-Khoury, Andreas Rieckmann, Jessica Bengtsson, Maria Melchior, Naja Hulvej Rod. Childhood adversity trajectories and PTSD in young adulthood: A nationwide Danish register-based cohort study of more than one million individuals. Journal of Psychiatric Research, 2021, 136, pp.274280. 10.1016/j.jpsychires.2021.02.034 . hal-03181436

\section{HAL Id: hal-03181436 \\ https://hal.sorbonne-universite.fr/hal-03181436}

Submitted on 25 Mar 2021

HAL is a multi-disciplinary open access archive for the deposit and dissemination of scientific research documents, whether they are published or not. The documents may come from teaching and research institutions in France or abroad, or from public or private research centers.
L'archive ouverte pluridisciplinaire HAL, est destinée au dépôt et à la diffusion de documents scientifiques de niveau recherche, publiés ou non, émanant des établissements d'enseignement et de recherche français ou étrangers, des laboratoires publics ou privés. 


\title{
Childhood adversity trajectories and PTSD in young adulthood:
}

\section{a nationwide Danish register-based cohort study of more than one}

\section{million individuals}

\begin{abstract}
We examine the association between trajectories of childhood adversities and Post-Traumatic Stress Disorder (PTSD) using a register-based Danish cohort.

The DANish LIFE Course (DANLIFE) cohort includes and prospectively follows all individuals born in Denmark from 1980. We estimated the rate of PTSD diagnosed from age 16, according to childhood adversity trajectories from age 0 to $16(n=1277548)$. Trajectories were previously defined into 5 groups: Low Adversity, Early Life Material Deprivation, Persistent Material Deprivation, Loss or Threat of Loss, And High Adversity. We then estimated adjusted relative hazard ratios (aHR), and absolute hazards differences of PTSD according to childhood adversity trajectories in adjusted survival analysis. All analyses were stratified by sex.

Individuals were followed for a median of 10.1 years after their 16th birthday, and 4966 individuals were diagnosed with PTSD. Compared with the low adversity group, children exposed to childhood adversity were more likely to be diagnosed with PTSD. The aHR for PTSD varied from 1.4 (95\% CI: 1.3 - 1.5) in the Early Life Material Deprivation group, to $3.7(3.3-4 \cdot 1)$ in the High Adversity group, which corresponds to 8.3 extra cases of PTSD per 10000 person years. The relative associations were comparable in men and women, but approximately twice as many women compared with men were affected.
\end{abstract}

We report a clear association between exposure to childhood adversities and PTSD in young adulthood. The highest burden was among women in the high adversity group.

\section{Keywords}

PTSD, childhood adversities, register-based cohort, early material deprivation. 


\section{Introduction}

Childhood adversity is the experience of early-life negative events such as abuse, neglect, or an unstable or deprived care environment (Finkelhor et al., 2013; Taylor-Robinson et al., 2018). In Europe, at least one in five children is reportedly exposed to a negative life event, with a small percentage (3 to $4 \%$ ) exposed to persisting and multiple adversities during childhood (Björkenstam et al., 2018; Vanaelst et al., 2012).

These experiences are linked with ahigher lifetime risk of poor physical and mental health (Ehlert, 2013; Kalmakis and Chandler, 2015), likely through different and multidimensional cognitive, behavioral, and neurobiological pathways (Fagundes et al., 2013). Childhood adversity has, for example, been associated with alterations in brain structure and functioning, particularly during stress-sensitive developmental periods, which increases the risk of difficulties in emotional and behavioral regulation, and atypical responsiveness to stressors in later life (Berens et al., 2017; Fagundes et al., 2013; McCrory et al., 2012). In turn, these alterations predispose to the development of stress-related psychopathology such as Post-Traumatic Stress Disorder (PTSD) (McLaughlin et al., 2017; Yehuda et al., 2010). Other proposed mechanisms linking childhood adversity to PTSD include impaired ability to form social connections, which are an important protective factor in resilience to stress (Kwong, 2014; Sperry and Widom, 2013; Stevens et al., 2013).

Multiple epidemiological studies have reported a higher risk of PTSD among individuals who experienced childhood adversity, postulating a 'sensitization' to the consequences of potential adversity later in life (Kalmakis and Chandler, 2015; McLaughlin et al., 2017, 2010; Schalinski et al., 2016). However, most studies in this area suffer from limitations such as sampling and selection bias, especially among participants who suffered childhood adversity (Doidge et al., 2017). In fact, individuals at risk of childhood adversities are less likely to participate in questionnaire-based studies, and they are also more like to be lost-to-follow-up (Chang et al., 2015). Additionally, many studies rely upon retrospective self-reports of childhood adversity, which are susceptible to memory bias. These biases have made it difficult to validly quantify the relation between childhood adversities and PTSD.

To date, most studies examined the effects of a single type of childhood adversity, such as parental loss, adverse parenting practices, or abuse (Nickerson et al., 2013; Schoedl et al., 2010). Therefore, the cumulative effects of different types of childhood adversities, their severity and their duration, which can moderate mental health effects, are not well known (Putnam et al., 2013).

In this study, we hypothesize that accumulation of childhood adversities - which include material deprivation, loss of a close family member and family dynamics - are related to a higher risk of PTSD in young adulthood. We also hypothesize that this relationship is stronger in women than in men, as women are more vulnerable to the consequences of trauma, and/or are at a higher risk of interpersonal victimization such as sexual abuse (Perrin et al., 2014). We test these hypotheses using data from a Danish nationwide register-based life course 
cohort (DANLIFE), which includes more than 1 million children born between 1980 and 2001 followed to young adulthood.

\section{Methods}

\section{Study population}

DANLIFE is a prospective register-based cohort study set up to investigate the complex life course mechanisms linking childhood adversities to health and well-being in childhood, adolescence, and young adulthood (Bengtsson et al., 2019). The DANLIFE cohort includes all individuals born in Denmark from 1980 onwards. In this study, we take advantage of previously defined trajectories of childhood adversities from age 0 to 16 years in this cohort (Rod NH et al., 2020), and apply these to an updated version of DANLIFE with 1283955 children. We excluded individuals who had been diagnosed with PTSD before the age of 16 years ( $\mathrm{n}=423)$, and who had missing information on potential confounders ( $\mathrm{n}=5$ 984), leading to a total study population of 1277548 individuals (Figure 1).

\section{Childhood adversity trajectory groups}

Detailed information on the identification of 5 trajectories of childhood adversity in Danish individuals can be found elsewhere (Rod NH et al., 2020). In brief; the DANLIFE cohort includes information on 12 different childhood adversities, which were identified by linking each individual's unique personal identification number in the Danish nationwide official registers (such as the Income Statistics Register, the Danish Civil Registration System, and the Danish National Patient Register). These adversities were grouped into 3 dimensions based on a thorough literature review and agreed upon by a panel of experts in stress, child health, and psychology.

The three dimensions are:

- Material deprivation, i.e. family poverty and parental long-term unemployment.

- Loss or threat of loss within the family, i.e. parental severe somatic illness, sibling severe somatic illness, and death of a parent or a sibling.

- Family dynamics, i.e. maternal separation, being placed in foster care, parental psychiatric illness, sibling psychiatric illness, and parental alcohol or drug abuse.

The adversities included in each dimension and the registers providing the information are presented in Supplementary Table 1 .

All adversities were summed by age and dimension (e.g. if a child in his or her $7^{\text {th }}$ year had been registered in foster care and had a parent who abused drugs, the child had two adversities in the family dynamic dimension in his or her $7^{\text {th }}$ year). Group-based multi-trajectory modelling was used to identify 5 common trajectories 
across age and adversity dimensions (Nagin et al., 2018). Multiple sensitivity analyses were conducted to ensure the robustness of the trajectories.

Five groups were identified and labeled: Low Adversity (54\% of the children): very low rate of adversities in all dimensions throughout childhood; Early Life Material Deprivation (20\% of the children): high annual rate of material deprivation during the first 4-5 years of life followed by a sharp decrease; Persistent Material Deprivation (13\% of the children): high annual rate of material deprivation during the entire childhood, but with a low rate of adversities in the two other dimensions; Loss or Threat of Loss (9\% of the children): relatively high and increasing annual rate of loss or threat of loss during the course of childhood, but low rates of adversities in the two other dimensions; and High Adversity (3\% of the children): high and increasing annual rate of adversities in all three dimensions.

\section{PTSD}

PTSD was defined according to the International Classification of Diseases $10^{\text {th }}$ revision (ICD-10, F43.1) (World Health Organization, 1992, p. 10). We used data from the Danish Psychiatric Central Research Register (all primary and secondary diagnoses and all patient types) (Mors et al., 2011). It is mandatory for all Danish hospitals to report to this register and the codes were given by the psychiatrist responsible for treating the patient. The validity of the PTSD diagnosis in the Danish registers vs. clinical evaluation has previously been established as being high (Svensson et al., 2015).

\section{Covariates}

Included potential confounders were parental education defined as the household highest attained education at the time of birth (low $\leq 9$ years, middle 10-12 years, and high $>12$ years), maternal age at the time of birth ( $<$ 20 years, 20-30 years, $>30$ years), maternal living situation at the time of birth (mother living with a partner, yes/no), the child's sex, birth year (1980-84, 1985-89, 1990-94, 1995-2001), and parental region of origin (European descent [including Europe, North America, Australia and New Zealand], non-European descent of at least one parent). In sensitivity analysis, birthweight was tested as another covariate but was not included in the main analyses, since maternal adversities could result in low birth weight, and could also be correlated with early life childhood adversities.

\section{Statistical analysis}

We described the rate of PTSD by age and by sex, among children with valid data on childhood adversity trajectories and PTSD at any time between birth and follow up $(n=1283$ 955; Figure 2), using a Poisson regression with a spline with 6 degrees of freedom. We used delayed entry at the calendar year 1994, since ICD-10 PTSD diagnoses is only available from 1994, to prevent underestimating the rate in early age by adding risk free time. All other analyses were carried out on the final study sample, where PTSD cases occurring before 16 years of age were excluded and only individuals with complete data on all covariates were analyzed ( $n=1277$ 548, Figure 2). 
In our main analysis, we estimated the rate of PTSD according to childhood adversity trajectories. We estimated unadjusted and adjusted relative hazard ratios (HR) using Cox proportional hazards models and absolute hazards differences (HD) using Aalen additive hazards models with age as the underling time unit (Madadizadeh et al., 2017). Individuals were followed from age 16 years until the first diagnosis of PTSD disorder or censoring (emigration, death, or the $31^{\text {st }}$ of December 2018), whichever occurred first. All analyses were stratified by sex. We created smoothed (spline with 6 degrees of freedom) cumulative incidence plots to assess the assumptions of constant hazards and the proportional hazards. In a sensitivity analysis, we assessed whether additional adjustment for birth weight changed the conclusion in a restricted study population who had full information on this variable. We used Stata for data preparation and R to estimate the hazard ratios and hazard differences using the packages "survival" and "timereg" (Martinussen and Holst, 2020, 2020).

\section{Ethical permission}

Studies based on the Danish register data do not require ethical permission by the Danish authorities. The study was approved by the Danish Data Protection Agency through the joint notification of The Faculty of Health and Medical Sciences at The University of Copenhagen (Ref no. 514-0262/18-3000). 


\section{Results}

The median follow-up time for participants after their $16^{\text {th }}$ birthday was 10.1 years (total number of person years = 13795 905), and 4966 individuals were diagnosed with PTSD. The rate of PTSD increased with age and sex, female participants systematically presenting higher rates compared to their male counterparts (Figure 2). Since not all participants had the same length of follow-up and less than half were followed until their $27^{\text {th }}$ birthday, confidence intervals surrounding the cumulative rate of PTSD after age 30 years are broader.

Table 1 presents characteristics of study participants according to their PTSD status. In addition to childhood adversity trajectories, having a parent with low educational level, having a teenage mother, and being a woman were associated with a higher risk of PTSD.

Figure 3 presents the cumulative incidence of PTSD across childhood adversity groups. Compared to the other groups, the incidence among the high adversity group increased after the age of 30 years especially among women.

Table 2 presents results from the adjusted and unadjusted survival analyses. Compared with individuals in the Low Adversity group, the adjusted hazard ratios (aHR) for PTSD were 1.4 (95\% CI: 1.3 - 1.5) in the Early Life Material Deprivation group, 1.8 (95\% CI: 1.7 - 2.0) in the Persistent Material Deprivation Group, and $2 \cdot 3$ (95\% CI: $2 \cdot 1-2 \cdot 5)$ in the Loss or Threat of Loss group. The highest aHR was observed among participants belonging to the High Adversity group (aHR=3.7; 95\% CI: $3 \cdot 3-4 \cdot 1$ ), corresponding to an adjusted $8 \cdot 3$ (95\% CI 7.3 -9.4) extra cases of PTSD per 10000 person years (pyrs) compared with the Low Adversity group.

In analyses stratified by sex (Table 2), the same relative patterns were observed. However, due to the overall higher PTSD rate among women compared with men, the hazard differences were considerably higher among women: childhood adversity trajectories explained around two times more PTSD cases per 10000 pyrs in women compared with men.

In sensitivity analysis, additional adjusting for birth weight did not change the associations between childhood adversity trajectories and PTSD (supplementary table 2).

\section{Discussion}

Based on unselected nationwide data covering more than 1 million children followed prospectively from birth, we found a clear association between exposure to childhood adversity and PTSD in young adulthood.

Children who experienced early life or persistent material deprivation, lived a loss or threat of loss experience, or were exposed to a high level of adversity had a higher risk of being diagnosed with PTSD in early adult life compared with those experiencing low levels of adversity. In stratified analyses, these associations were 
comparable in men and women, but the number of extra cases of PTSD explained by childhood adversity was higher among women because of their higher rate of PTSD. Overall, these findings indicate that early life experiences can increase the risk of PTSD in young adulthood, suggesting that efforts aimed at preventing PTSD should take into consideration individuals' lifelong vulnerability.

\section{Strengths and limitations}

Strengths of our investigation include a population-based unselected sample with prospective ascertainment of the relationship between childhood adversities and PTSD. PTSD is thought to be cyclical, with periods of diminished as well as heightened emotional responses, which may lead to misclassification in cross-sectional (Batelaan et al., 2017; Pérez Benítez et al., 2013), or retrospective studies (Sheikh, 2018). Additionally, attrition is a major concern in previous prospective studies, where disadvantaged backgrounds and mental health problems including PTSD were found to predict lower levels of continued participation over time (Marryat and Frank, 2019; Meinck et al., 2015) . Our use of nationwide data, with quasi-complete registerbased follow-up, eliminated concerns about attrition bias in the present study.

We measured PTSD diagnosis in Danish registers and it is possible that some PTSD occurrences were not identified. There is also possible non-differential misclassification of some adversities ascertained, such as psychiatric illness (hospitalizations), or alcohol and drug abuse (ICD codes and prescriptions). Also, no specific data on child physical or sexual abuse, which are known to be associated with PTSD (Friedman et al., 2011; Schoedl et al., 2010), could be collected from the registers, which is an significant limitation of our study. However, it is likely that children who experience high levels of adversity are at especially high risk of these forms of violence, since traumatic events often co-occur (Morgan and Gayer-Anderson, 2016). For example, material deprivation and family dysfunction are correlated with child maltreatment as well as with physical and sexual abuse (Eckenrode et al., 2014; Kim et al., 2017; MacMillan et al., 2013). Thus, it is possible that we were able to account for part of individuals' vulnerability related to early life physical or sexual abuse by measuring persistent high-level adversity. Future studies should systematically take into account childhood sexual abuse when examining the association between childhood adversities and anxiety disorders such as PTSD.

\section{Interpretation}

The findings of the present study are broadly consistent with an extensive literature on the effects of childhood adversity, abuse, and maltreatment on stress-related symptoms later in life, mostly studied in small clinical samples (Kalmakis and Chandler, 2015; Schalinski et al., 2016). We advance this literature by confirming these findings in a much larger unselected population sample continuously followed from birth until young adulthood, and by systematically examining sex differences. Adversity during childhood and adolescence has been reported to have deleterious effects on the development and acquisition of interpersonal and emotionregulation skills (Sperry and Widom, 2013; Yehuda et al., 2010), notably the development of the hypothalamic-pituitary-adrenal (HPA) axis (Berens et al., 2017). Emotional dysregulation is linked with diminished self-control and inadequate responses to environmental demands, including stressful events, and 
has been reported to mediate the association between childhood adversity and PTSD (Burns et al., 2010). Further, early negative experiences can become internalized as maladaptive mental representations (e.g. mistrust, abuse, abandonment, defectiveness, and shame) and shape reactions to later interpersonal situations, which also mediate the effects of early childhood adversity on later psychosocial difficulties in adulthood (Harding et al., 2012).

We find a markedly higher risk of PTSD among individuals with high levels of childhood adversities and more persistent material deprivation compared with those who experienced low levels of adversity. These findings contribute to mounting evidence of a potential causal mechanism linking cumulative and intense negative events in childhood to psychopathology later in life. Another proposed mechanism is a higher risk of feelings of social disconnection embedded from early childhood following adversity, which may lead to difficulties in securing supportive social bonds, a protective factor in coping with stress and stressors (Sperry and Widom, 2013). Individuals who experience high levels of adversity during childhood could also be more likely to suffer other forms of victimization and traumatic events during their adult life due to common environmental and socio-economic determinants, therefore further increasing their risk of PTSD.

These findings also confirm the importance of examining different dimensions of childhood adversities as well as their intensity and recurrence to understand lifelong mental health (Putnam et al., 2013). Childhood trauma could cause persistent psychological distress and psychiatric disorder (Dye, 2018). Examining the timing of adversities may also be important to understanding pathways through which negative experiences affect health outcomes. Further, examining cumulative adversity gives a more robust account of individuals' exposure to stress than the experience of a single event or event category, such as parental neglect or social deprivation.

Another important finding of our study is that the relative effect of childhood adversity on the risk of PTSD was comparable in women and men. Sex differences commonly found in PTSD prevalence therefore do not seem due to differences in responses to childhood adversity, even though there is some evidence of biological sex differences in neural processes related to individuals' response to stress (Frijling, 2017; Shansky, 2015). Although men are more exposed to violence and traumatic events, it is possible that women are more exposed to high-impact trauma such as sexual violence, and at a younger age, which might explain sex-differences in PTSD risk independently of childhood adversities (Olff, 2017). Women are more likely to seek medical care, which might also, at least partly, explain our results (Twomey et al., 2015).

It has been suggested that stress generated by adversity experienced during childhood could alter central neurobiological systems, and damage the mechanisms of stress regulation in the brain, notably the HPA axis (Berens et al., 2017). This alteration predisposes to psychiatric vulnerability due to an increased risk of difficulties in emotional and behavioral regulation, and atypical responsiveness to stressors in later life. In fact, altered levels and signaling capacity of cortisol, a glucocorticoid class of steroid hormone the production 
of which is triggered by the HPA axis, is thought to increase the risk of developing stress-related psychopathology such as PTSD (Yehuda et al., 2010).

\section{Conclusion}

Our results offer insight into the links between different common types of childhood adversity trajectories and subsequent PTSD in a large unselected population sample followed from birth into adult life. We find a moderately higher risk of PTSD among individuals who have experienced persistent material deprivation or loss or threats of loss in the family during childhood, compared with individuals with low levels of adversity during childhood. A small group of individuals experience high levels of childhood adversities during their entire childhood, and these individuals seem to constitute a particularly vulnerable group with a more than threefold risk of PTSD in adult life compared with individuals with a low level of adversities during childhood. While the relative effects are similar in men and women, the absolute effects are strongest in women due to their higher incidence of PTSD. Our findings also highlight the importance of structural interventions to end childhood poverty and other childhood adversities driven by social inequalities. 


\section{Contributors}

FEKL, AR, MM, and NHR were involved in the conception of the analysis.

JB and NHR were involved in the conception and design of the cohort.

AR was responsible for data management and analyses.

All authors contributed to the writing of the manuscript and have critically revised and approved the final version.

\section{Conflicts of interest}

The authors report declare no conflicts of interest

\section{Funding}

None to declare 


\section{References}

Batelaan, N.M., Bosman, R.C., Muntingh, A., Scholten, W.D., Huijbregts, K.M., Balkom, A.J.L.M. van, 2017. Risk of relapse after antidepressant discontinuation in anxiety disorders, obsessivecompulsive disorder, and post-traumatic stress disorder: systematic review and meta-analysis of relapse prevention trials. BMJ 358, j3927. https://doi.org/10.1136/bmj.j3927

Bengtsson, J., Dich, N., Rieckmann, A., Rod, N.H., 2019. Cohort profile: the DANish LIFE course (DANLIFE) cohort, a prospective register-based cohort of all children born in Denmark since 1980. BMJ Open 9, e027217. https://doi.org/10.1136/bmjopen-2018-027217

Berens, A.E., Jensen, S.K.G., Nelson, C.A., 2017. Biological embedding of childhood adversity: from physiological mechanisms to clinical implications. BMC Med. 15, 135. https://doi.org/10.1186/s12916-017-0895-4

Björkenstam, E., Hjern, A., Björkenstam, C., Kosidou, K., 2018. Association of Cumulative Childhood Adversity and Adolescent Violent Offending With Suicide in Early Adulthood. JAMA Psychiatry 75, 185-193. https://doi.org/10.1001/jamapsychiatry.2017.3788

Burns, E.E., Jackson, J.L., Harding, H.G., 2010. Child Maltreatment, Emotion Regulation, and Posttraumatic Stress: The Impact of Emotional Abuse. J. Aggress. Maltreatment Trauma 19, 801-819. https://doi.org/10.1080/10926771.2010.522947

Chang, H.Y., Chung, Y., Keyes, K.M., Jung, S.J., Kim, S.-S., 2015. Associations between the timing of childhood adversity and adulthood suicidal behavior: A nationally-representative cohort. J. Affect. Disord. 186, 198-202. https://doi.org/10.1016/j.jad.2015.06.025

Doidge, J.C., Edwards, B., Higgins, D.J., Segal, L., 2017. Adverse childhood experiences, nonresponse and loss to follow-up: Findings from a prospective birth cohort and recommendations for addressing missing data. Longitud. Life Course Stud. 8, 382-400. https://doi.org/10.14301/llcs.v8i4.414

Dye, H., 2018. The impact and long-term effects of childhood trauma. J. Hum. Behav. Soc. Environ. 28, 381-392. https://doi.org/10.1080/10911359.2018.1435328

Eckenrode, J., Smith, E.G., McCarthy, M.E., Dineen, M., 2014. Income inequality and child maltreatment in the United States. Pediatrics 133, 454-461. https://doi.org/10.1542/peds.20131707

Ehlert, U., 2013. Enduring psychobiological effects of childhood adversity. Psychoneuroendocrinology 38, 1850-1857. https://doi.org/10.1016/j.psyneuen.2013.06.007

Fagundes, C.P., Glaser, R., Kiecolt-Glaser, J.K., 2013. Stressful early life experiences and immune dysregulation across the lifespan. Brain. Behav. Immun. 27, 8-12. https://doi.org/10.1016/j.bbi.2012.06.014

Finkelhor, D., Shattuck, A., Turner, H., Hamby, S., 2013. Improving the Adverse Childhood Experiences Study Scale. JAMA Pediatr. 167, 70. https://doi.org/10.1001/jamapediatrics.2013.420

Friedman, M.S., Marshal, M.P., Guadamuz, T.E., Wei, C., Wong, C.F., Saewyc, E., Stall, R., 2011. A meta-analysis of disparities in childhood sexual abuse, parental physical abuse, and peer victimization among sexual minority and sexual nonminority individuals. Am. J. Public Health 101, 1481-1494. https://doi.org/10.2105/AJPH.2009.190009

Frijling, J.L., 2017. Preventing PTSD with oxytocin: effects of oxytocin administration on fear neurocircuitry and PTSD symptom development in recently trauma-exposed individuals. Eur. J. Psychotraumatology 8, 1302652. https://doi.org/10.1080/20008198.2017.1302652

Harding, H.G., Burns, E.E., Jackson, J.L., 2012. Identification of Child Sexual Abuse Survivor Subgroups Based on Early Maladaptive Schemas: Implications for Understanding Differences in Posttraumatic Stress Disorder Symptom Severity. Cogn. Ther. Res. 36, 560-575. https://doi.org/10.1007/s10608-011-9385-8

Kalmakis, K.A., Chandler, G.E., 2015. Health consequences of adverse childhood experiences: A systematic review: J. Am. Assoc. Nurse Pract. 27, 457-465. https://doi.org/10.1002/23276924.12215 
Kim, K., Mennen, F.E., Trickett, P.K., 2017. Patterns and correlates of co-occurrence among multiple types of child maltreatment. Child Fam. Soc. Work 22, 492-502. https://doi.org/10.1111/cfs. 12268

Kwong, T., 2014. Adverse Childhood Experiences (aces) And Their Influence On Social Connectedness. Public Health Theses.

MacMillan, H.L., Tanaka, M., Duku, E., Vaillancourt, T., Boyle, M.H., 2013. Child physical and sexual abuse in a community sample of young adults: Results from the Ontario Child Health Study. Child Abuse Negl., Special Issue on Risk and Resilience in the Context of Child Maltreatment (Part 1) 37, 14-21. https://doi.org/10.1016/j.chiabu.2012.06.005

Madadizadeh, F., Ghanbarnejad, A., Ghavami, V., Bandamiri, M.Z., Mohammadianpanah, M., 2017. Applying Additive Hazards Models for Analyzing Survival in Patients with Colorectal Cancer in Fars Province, Southern Iran. Asian Pac. J. Cancer Prev. APJCP 18, 1077-1083. https://doi.org/10.22034/APJCP.2017.18.4.1077

Marryat, L., Frank, J., 2019. Factors associated with adverse childhood experiences in Scottish children: a prospective cohort study. BMJ Paediatr. Open 3. https://doi.org/10.1136/bmjpo2018-000340

Martinussen, T.S. with contributions from T., Holst, J.S. and K., 2020. timereg: Flexible Regression Models for Survival Data.

McCrory, E., De Brito, S.A., Viding, E., 2012. The link between child abuse and psychopathology: A review of neurobiological and genetic research. J. R. Soc. Med. 105, 151-156. https://doi.org/10.1258/jrsm.2011.110222

McLaughlin, K.A., Conron, K.J., Koenen, K.C., Gilman, S.E., 2010. Childhood adversity, adult stressful life events, and risk of past-year psychiatric disorder: a test of the stress sensitization hypothesis in a population-based sample of adults. Psychol. Med. 40, 1647-1658. https://doi.org/10.1017/S0033291709992121

McLaughlin, K.A., Koenen, K.C., Bromet, E.J., Karam, E.G., Liu, H., Petukhova, M., Ruscio, A.M., Sampson, N.A., Stein, D.J., Aguilar-Gaxiola, S., Alonso, J., Borges, G., Demyttenaere, K., Dinolova, R.V., Ferry, F., Florescu, S., Girolamo, G. de, Gureje, O., Kawakami, N., Lee, S., Navarro-Mateu, F., Piazza, M., Pennell, B.-E., Posada-Villa, J., Have, M. ten, Viana, M.C., Kessler, R.C., 2017. Childhood adversities and post-traumatic stress disorder: evidence for stress sensitisation in the World Mental Health Surveys. Br. J. Psychiatry 211, 280-288. https://doi.org/10.1192/bjp.bp.116.197640

Meinck, F., Cluver, L.D., Boyes, M.E., 2015. Household illness, poverty and physical and emotional child abuse victimisation: findings from South Africa's first prospective cohort study. BMC Public Health 15, 444. https://doi.org/10.1186/s12889-015-1792-4

Morgan, C., Gayer-Anderson, C., 2016. Childhood adversities and psychosis: evidence, challenges, implications. World Psychiatry Off. J. World Psychiatr. Assoc. WPA 15, 93-102. https://doi.org/10.1002/wps.20330

Mors, O., Perto, G.P., Mortensen, P.B., 2011. The Danish Psychiatric Central Research Register. Scand. J. Public Health 39, 54-57. https://doi.org/10.1177/1403494810395825

Nagin, D.S., Jones, B.L., Passos, V.L., Tremblay, R.E., 2018. Group-based multi-trajectory modeling. Stat. Methods Med. Res. 27, 2015-2023. https://doi.org/10.1177/0962280216673085

Nickerson, A., Bryant, R.A., Aderka, I.M., Hinton, D.E., Hofmann, S.G., 2013. The impacts of parental loss and adverse parenting on mental health: Findings from the National Comorbidity Survey-Replication. Psychol. Trauma Theory Res. Pract. Policy 5, 119-127. https://doi.org/10.1037/a0025695

Olff, M., 2017. Sex and gender differences in post-traumatic stress disorder: an update. Eur. J. Psychotraumatology 8, 1351204. https://doi.org/10.1080/20008198.2017.1351204

Organization, W.H., 1992. The ICD-10 classification of mental and behavioural disorders : clinical descriptions and diagnostic guidelines. World Health Organization.

PÉREZ BENÍTEZ, C.I., ZLOTNICK, C., DYCK, I., STOUT, R., ANGERT, E., WEISBERG, R., KELLER, M., 2013. Predictors of the long-term course of comorbid PTSD: A naturalistic prospective study. Int. J. Psychiatry Clin. Pract. 17, 232-237. https://doi.org/10.3109/13651501.2012.667113 
Perrin, M., Vandeleur, C.L., Castelao, E., Rothen, S., Glaus, J., Vollenweider, P., Preisig, M., 2014. Determinants of the development of post-traumatic stress disorder, in the general population. Soc. Psychiatry Psychiatr. Epidemiol. 49, 447-457. https://doi.org/10.1007/s00127-013-07623

Putnam, K.T., Harris, W.W., Putnam, F.W., 2013. Synergistic Childhood Adversities and Complex Adult Psychopathology. J. Trauma. Stress 26, 435-442. https://doi.org/10.1002/jts.21833

Rod NH, Bengtsson J, Budtz-Jørgensen E, Clipet-Jensen C, Taylor-Robinson D, Nybo Andersen AM, Dich N, Rieckmann A, Rod NH ; Bengtsson J ; Budtz-Jørgensen E ; Clipet-Jensen C ; Taylor-Robinson D; Nybo Andersen AM ; Dich N; Rieckmann A, 2020. Trajectories of childhood adversity and premature mortality in early adulthood: A population-based cohort study in Denmark.

Schalinski, I., Teicher, M.H., Nischk, D., Hinderer, E., Müller, O., Rockstroh, B., 2016. Type and timing of adverse childhood experiences differentially affect severity of PTSD, dissociative and depressive symptoms in adult inpatients. BMC Psychiatry 16, 295. https://doi.org/10.1186/s12888-016-1004-5

Schoedl, A.F., Costa, M.C.P., Mari, J.J., Mello, M.F., Tyrka, A.R., Carpenter, L.L., Price, L.H., 2010. The Clinical Correlates of Reported Childhood Sexual Abuse: An Association Between Age at Trauma Onset and Severity of Depression and PTSD in Adults. J. Child Sex. Abuse 19, 156170. https://doi.org/10.1080/10538711003615038

Shansky, R.M., 2015. Sex differences in PTSD resilience and susceptibility: Challenges for animal models of fear learning. Neurobiol. Stress 1, 60-65. https://doi.org/10.1016/j.ynstr.2014.09.005

Sheikh, M.A., 2018. Childhood adversities and chronic conditions: examination of mediators, recall bias and age at diagnosis. Int. J. Public Health 63, 181-192. https://doi.org/10.1007/s00038$017-1021-2$

Sperry, D.M., Widom, C.S., 2013. Child abuse and neglect, social support, and psychopathology in adulthood: A prospective investigation. Child Abuse Negl. 37, 415-425. https://doi.org/10.1016/j.chiabu.2013.02.006

Stevens, N.R., Gerhart, J., Goldsmith, R.E., Heath, N.M., Chesney, S.A., Hobfoll, S.E., 2013. Emotion Regulation Difficulties, Low Social Support, and Interpersonal Violence Mediate the Link Between Childhood Abuse and Posttraumatic Stress Symptoms. Behav. Ther. 44, 152-161. https://doi.org/10.1016/j.beth.2012.09.003

Svensson, E., Lash, T.L., Resick, P.A., Hansen, J.G., Gradus, J.L., 2015. Validity of reaction to severe stress and adjustment disorder diagnoses in the Danish Psychiatric Central Research Registry. Clin. Epidemiol. 7, 235-242. https://doi.org/10.2147/CLEP.S80514

Taylor-Robinson, D.C., Straatmann, V.S., Whitehead, M., 2018. Adverse childhood experiences or adverse childhood socioeconomic conditions? Lancet Public Health 3, e262-e263. https://doi.org/10.1016/S2468-2667(18)30094-X

Twomey, C.D., Baldwin, D.S., Hopfe, M., Cieza, A., 2015. A systematic review of the predictors of health service utilisation by adults with mental disorders in the UK. BMJ Open 5, e007575. https://doi.org/10.1136/bmjopen-2015-007575

Vanaelst, B., Huybrechts, I., De Bourdeaudhuij, I., Bammann, K., Hadjigeorgiou, C., Eiben, G., Konstabel, K., Michels, N., Molnar, D., Moreno, L.A., Pigeot, I., Reisch, L., Siani, A., Vyncke, K., De Henauw, S., 2012. Prevalence of negative life events and chronic adversities in European pre- and primary-school children: results from the IDEFICS study. Arch. Public Health 70, 26. https://doi.org/10.1186/0778-7367-70-26

Yehuda, R., Flory, J.D., Pratchett, L.C., Buxbaum, J., Ising, M., Holsboer, F., 2010. Putative biological mechanisms for the association between early life adversity and the subsequent development of PTSD. Psychopharmacology (Berl.) 212, 405-417.

https://doi.org/10.1007/s00213-010-1969-6 


\section{Tables and figures}

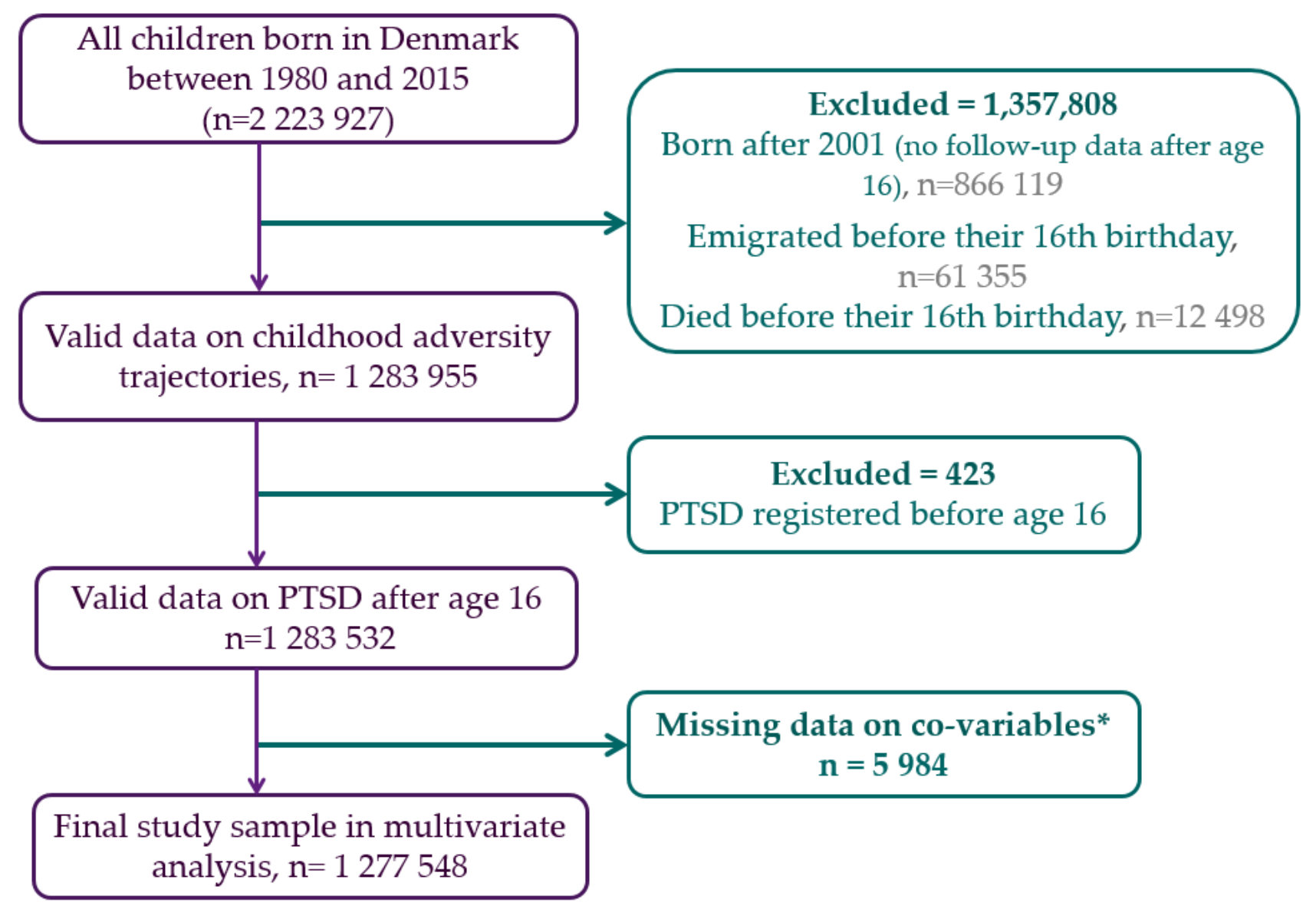

Figure 1: Flow chart of the study population included from the DANish LIFE Course (DANLIFE) cohort to examine the relationship between childhood adversity trajectories and Post-Traumatic Stress Disorder (PTSD).

* co-variables : Sex, parental education parental origin maternal age, and maternal living situation at the time of birth. 


\section{Rate of PTSD by age}

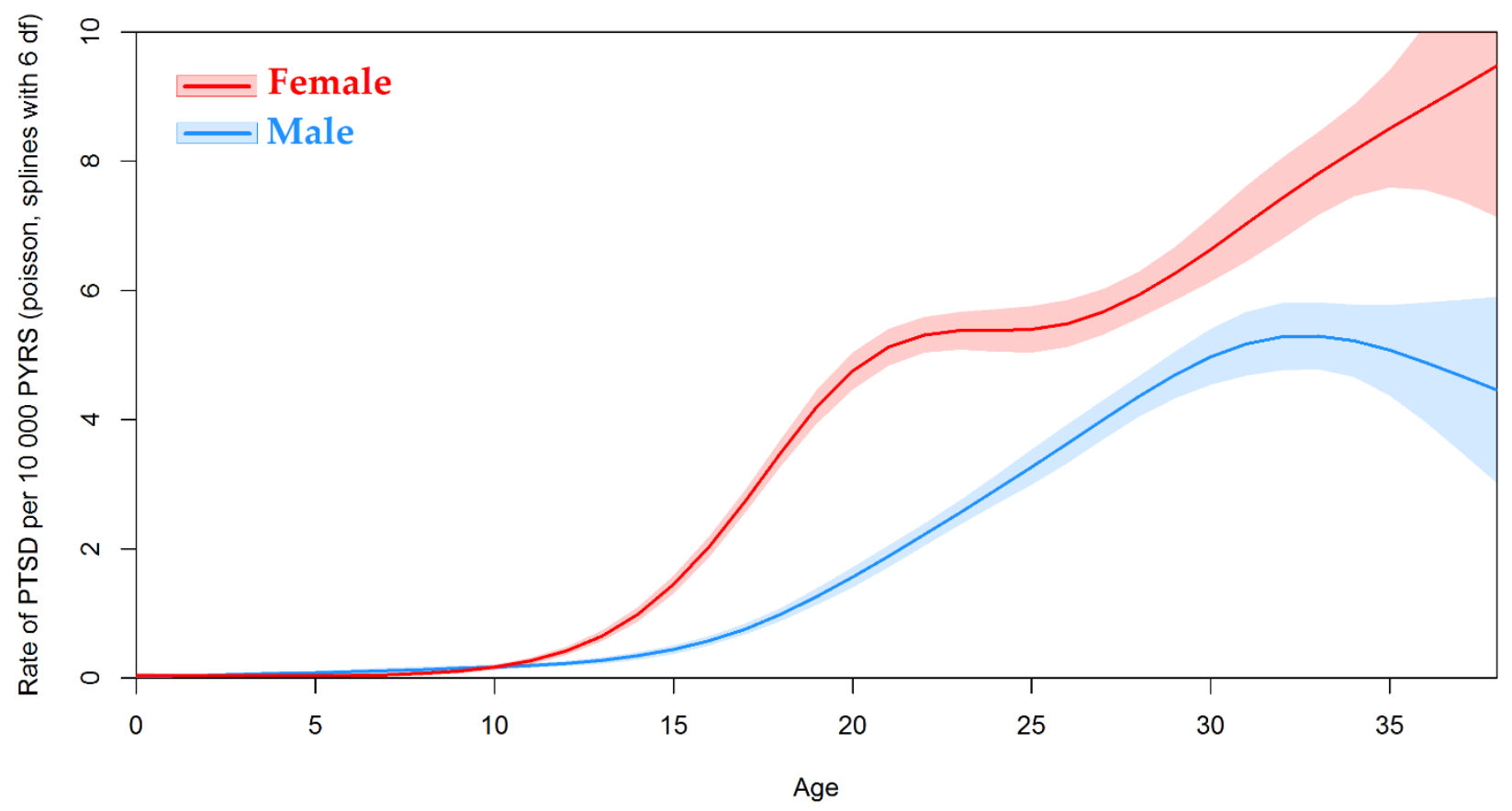

Figure 2: Cumulative Rate of Post-Traumatic Stress Disorder (PTSD) per 10000 person years (PYRS) by age and sex. Data for participants with valid data on childhood adversity trajectories (The DANish LIFE Course (DANLIFE) cohort, $n=1283$ 955).

We included delayed entry at the calendar year 1994 for these rates (to prevent underestimating the rate in early age / adding risk free time), since ICD-10 PTSD diagnoses is first available from then. 


\begin{tabular}{|c|c|c|c|}
\hline & $\begin{array}{c}\text { No PTSD } \\
(\mathrm{n}=1 \text { 272 582) }\end{array}$ & $\begin{array}{c}\text { PTSD } \\
(\mathrm{n}=4 \text { 966) }\end{array}$ & $\begin{array}{c}\text { Overall } \\
(n=1277548)\end{array}$ \\
\hline \multicolumn{4}{|l|}{ Childhood adversity trajectories } \\
\hline Low Adversity & $690626(54 \cdot 3 \%)$ & $1536(30 \cdot 9 \%)$ & $692162(54 \cdot 2 \%)$ \\
\hline Early Life Material Deprivation & $255687(20 \cdot 1 \%)$ & $1074(21 \cdot 6 \%)$ & $256761(20 \cdot 1 \%)$ \\
\hline Persistent Material Deprivation & $169147(13 \cdot 3 \%)$ & $1097(22 \cdot 1 \%)$ & $170244(13 \cdot 3 \%)$ \\
\hline Loss or Threat of Loss & $116675(9 \cdot 2 \%)$ & $686(13 \cdot 8 \%)$ & $117361(9 \cdot 2 \%)$ \\
\hline High Adversity & $40447(3 \cdot 2 \%)$ & $573(11 \cdot 5 \%)$ & $41020(3 \cdot 2 \%)$ \\
\hline \multicolumn{4}{|l|}{ Parental education at birth } \\
\hline Low & $211069(16 \cdot 6 \%)$ & $1770(35 \cdot 6 \%)$ & $212839(16 \cdot 7 \%)$ \\
\hline Intermediate & $629746(49 \cdot 5 \%)$ & $2319(46 \cdot 7 \%)$ & $632065(49 \cdot 5 \%)$ \\
\hline High & $431767(33.9 \%)$ & $877(17 \cdot 7 \%)$ & $432644(33 \cdot 9 \%)$ \\
\hline \multicolumn{4}{|l|}{ Maternal age at birth } \\
\hline$<20 \mathrm{yrs}$ & $34163(2 \cdot 7 \%)$ & $366(7 \cdot 4 \%)$ & $34529(2 \cdot 7 \%)$ \\
\hline $20-30 \mathrm{yrs}$ & $855443(67 \cdot 2 \%)$ & $3595(72 \cdot 4 \%)$ & $859038(67 \cdot 2 \%)$ \\
\hline$\geq 30 \mathrm{yrs}$ & $382976(30 \cdot 1 \%)$ & $1005(20 \cdot 2 \%)$ & $383981(30 \cdot 1 \%)$ \\
\hline \multicolumn{4}{|l|}{$\begin{array}{c}\text { Mother living with a partner at } \\
\text { birth }\end{array}$} \\
\hline No & $180772(14 \cdot 2 \%)$ & $1219(24 \cdot 5 \%)$ & $181991(14 \cdot 2 \%)$ \\
\hline Yes & $1091810(85 \cdot 8 \%)$ & $3747(75 \cdot 5 \%)$ & $1095557(85 \cdot 8 \%)$ \\
\hline \multicolumn{4}{|l|}{ Sex } \\
\hline Male & $653642(51 \cdot 4 \%)$ & $1747(35 \cdot 2 \%)$ & $655389(51 \cdot 3 \%)$ \\
\hline Female & $618940(48 \cdot 6 \%)$ & $3219(64 \cdot 8 \%)$ & $622159(48 \cdot 7 \%)$ \\
\hline \multicolumn{4}{|l|}{ Parental region of origin } \\
\hline Other countries & $33925(2 \cdot 7 \%)$ & $115(2 \cdot 3 \%)$ & $34040(2 \cdot 7 \%)$ \\
\hline $\begin{array}{l}\text { Europe, USA, Australia, or New } \\
\text { Zealand }\end{array}$ & $1238657(97 \cdot 3 \%)$ & $4851(97 \cdot 7 \%)$ & $1243508(97 \cdot 3 \%)$ \\
\hline
\end{tabular}

Table 1: Characteristics of study participants according to Post-Traumatic Stress Disorder (PTSD) status.

DANLIFE cohort, $\mathrm{n}=1277548$, total number of person years = 13795905 . 
Men

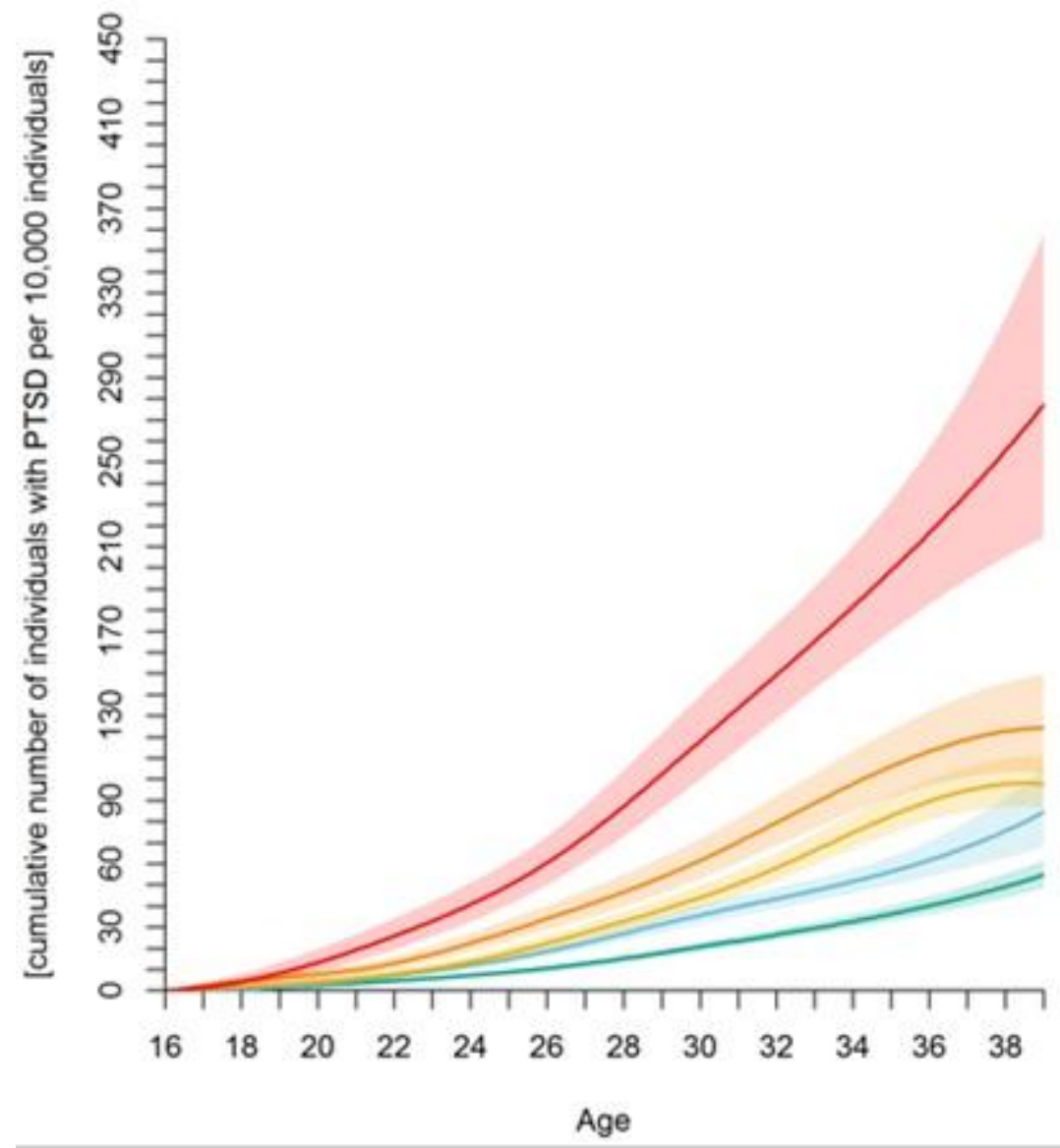

Women

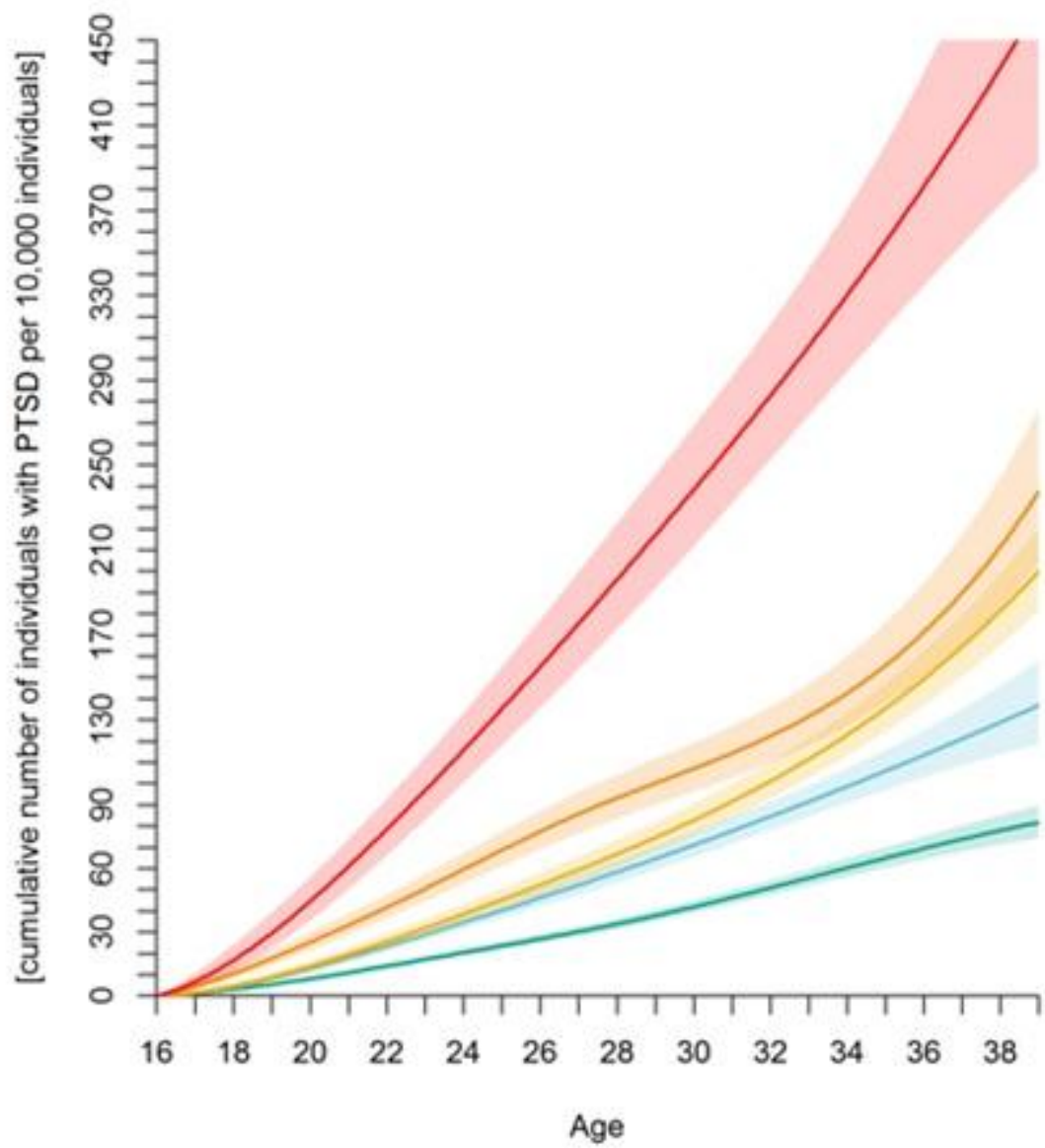

\section{Childhood adversity trajectory groups}

\begin{tabular}{|l|l|c|c|c|}
\hline Low adversity & $\begin{array}{c}\text { Early Life Material } \\
\text { Deprivation }\end{array}$ & $\begin{array}{c}\text { Persistent Material } \\
\text { Deprivation }\end{array}$ & $\begin{array}{c}\text { Loss or Threat of } \\
\text { Loss }\end{array}$ & High Adversity \\
\hline
\end{tabular}

Figure 3 : Cumulative incidence plots of PTSD occurrence according to childhood adversities, and sex. Data from the DANLIFE cohort (n=1 277 548) 


\begin{tabular}{|c|c|c|c|c|c|c|c|c|c|c|c|c|c|c|c|}
\hline & \multicolumn{5}{|c|}{ Overall } & \multicolumn{5}{|c|}{ Men } & \multicolumn{5}{|c|}{ Women } \\
\hline & $\begin{array}{c}\text { Cases } \\
\text { (rate } \\
\text { per } \\
\text { 10000 } \\
\text { PYRS) }\end{array}$ & $\begin{array}{c}\text { HR } \\
(95 \% \mathrm{CI})\end{array}$ & $\begin{array}{c}\text { aHR } \\
(95 \% \mathrm{CI})\end{array}$ & $\begin{array}{c}\text { HD } \\
\text { [addition } \\
\text { al cases } \\
\text { per } 10 \\
\text { 000 } \\
\text { PYRS] } \\
(95 \% \mathrm{CI})\end{array}$ & $\begin{array}{c}\text { aHD } \\
\text { [addition } \\
\text { al cases } \\
\text { per } 10 \\
000 \\
\text { PYRS] } \\
(95 \% \mathrm{CI})\end{array}$ & $\begin{array}{c}\text { Cases } \\
\text { (rate } \\
\text { per } \\
\text { 10000 } \\
\text { PYRS) }\end{array}$ & $\begin{array}{c}\text { HR } \\
(95 \% \mathrm{CI})\end{array}$ & $\begin{array}{c}\text { aHR } \\
(95 \% \mathrm{CI})\end{array}$ & $\begin{array}{c}\text { HD } \\
\text { [addition } \\
\text { al cases } \\
\text { per } 10 \\
000 \\
\text { PYRS] } \\
(95 \% \text { CI })\end{array}$ & $\begin{array}{c}\text { aHD } \\
\text { [addition } \\
\text { al cases } \\
\text { per } 10 \\
000 \\
\text { PYRS] } \\
(95 \% \mathrm{CI})\end{array}$ & $\begin{array}{c}\text { Cases } \\
\text { (rate } \\
\text { per } \\
\text { 10000 } \\
\text { PYRS) }\end{array}$ & HR & aHR & $\begin{array}{c}\text { HD } \\
\text { [addition } \\
\text { al cases } \\
\text { per } 10 \\
000 \\
\text { PYRS] } \\
(95 \% \mathrm{CI})\end{array}$ & $\begin{array}{c}\text { aHD } \\
\text { [addition } \\
\text { al cases } \\
\text { per } 10 \\
000 \\
\text { PYRS] } \\
(95 \% \mathrm{CI})\end{array}$ \\
\hline $\begin{array}{c}\text { Low } \\
\text { Adversity }\end{array}$ & $\begin{array}{l}1536 \\
(2 \cdot 2)\end{array}$ & 1 (ref) & 1 (ref) & 0 (ref) & 0 (ref) & $\begin{array}{l}525 \\
(1 \cdot 4)\end{array}$ & 1 (ref) & 1 (ref) & 0 (ref) & 0 (ref) & $\begin{array}{c}1011 \\
(3)\end{array}$ & 1 (ref) & 1 (ref) & 0 (ref) & 0 (ref) \\
\hline $\begin{array}{c}\text { Early Life } \\
\text { Material } \\
\text { Deprivation }\end{array}$ & $\begin{array}{l}1074 \\
(3 \cdot 7)\end{array}$ & $\begin{array}{c}1 \cdot 7 \\
(1 \cdot 5-1 \cdot 8)\end{array}$ & $\begin{array}{c}1 \cdot 4 \\
(1 \cdot 3-1 \cdot 5)\end{array}$ & $\begin{array}{c}(1 \cdot 2- \\
1 \cdot 7)\end{array}$ & $\begin{array}{c}0 \cdot 8 \\
(0 \cdot 6-1 \cdot 1)\end{array}$ & $\begin{array}{l}364 \\
(2 \cdot 4)\end{array}$ & $\begin{array}{c}1 \cdot 6 \\
(1 \cdot 4-1 \cdot 9)\end{array}$ & $\begin{array}{c}1 \cdot 4 \\
(1 \cdot 2-1 \cdot 6)\end{array}$ & $\begin{array}{c}0 \cdot 9 \\
(0 \cdot 6-1 \cdot 2)\end{array}$ & $\begin{array}{c}0 \cdot 5 \\
(0 \cdot 2-0 \cdot 7)\end{array}$ & $\begin{array}{l}710 \\
(5)\end{array}$ & $\begin{array}{c}1 \cdot 7 \\
(1 \cdot 5-1 \cdot 8)\end{array}$ & $\begin{array}{c}1 \cdot 4 \\
(1 \cdot 3-1 \cdot 6)\end{array}$ & $\begin{array}{l}2 \cdot 0 \\
(1 \cdot 6- \\
2 \cdot 4)\end{array}$ & $\begin{array}{c}1 \cdot 2 \\
(0 \cdot 8- \\
1 \cdot 6)\end{array}$ \\
\hline $\begin{array}{c}\text { Persistent } \\
\text { Material } \\
\text { Deprivation }\end{array}$ & $\begin{array}{c}1097 \\
(5)\end{array}$ & $\begin{array}{c}2 \cdot 1 \\
(2 \cdot 0-2 \cdot 3)\end{array}$ & $\begin{array}{c}1 \cdot 8 \\
(1 \cdot 7-2 \cdot 0)\end{array}$ & $\begin{array}{l}(2 \cdot 2- \\
2 \cdot 8)\end{array}$ & $\begin{array}{c}1 \cdot 9 \\
(1 \cdot 5-2 \cdot 2)\end{array}$ & $\begin{array}{l}400 \\
(3 \cdot 5)\end{array}$ & $\begin{array}{c}2 \cdot 2 \\
(1 \cdot 9-2 \cdot 5)\end{array}$ & $\begin{array}{c}1 \cdot 8 \\
(1 \cdot 6-2 \cdot 1)\end{array}$ & $\begin{array}{c}1 \cdot 8 \\
(1 \cdot 4-2 \cdot 1)\end{array}$ & $\begin{array}{c}1 \cdot 3 \\
(0 \cdot 9-1 \cdot 7)\end{array}$ & $\begin{array}{c}697 \\
(6 \cdot 5)\end{array}$ & $\begin{array}{c}2 \cdot 1 \\
(1 \cdot 9-2 \cdot 3)\end{array}$ & $\begin{array}{c}1 \cdot 8 \\
(1 \cdot 6-2 \cdot 0)\end{array}$ & $\begin{array}{l}3 \cdot 3 \\
(2 \cdot 8- \\
3 \cdot 8)\end{array}$ & $\begin{array}{l}2 \cdot 5 \\
(2 \cdot 0- \\
3 \cdot 0)\end{array}$ \\
\hline $\begin{array}{c}\text { Loss or } \\
\text { Threat of Loss } \\
\text { group }\end{array}$ & $\begin{array}{c}686 \\
(5 \cdot 9)\end{array}$ & $\begin{array}{c}2 \cdot 8 \\
(2 \cdot 5-3 \cdot 0)\end{array}$ & $\begin{array}{c}2 \cdot 3 \\
(2 \cdot 1-2 \cdot 5)\end{array}$ & $\begin{array}{l}3 \cdot 8 \\
(3 \cdot 4- \\
4 \cdot 3)\end{array}$ & $\begin{array}{c}3 \cdot 1 \\
(2 \cdot 7-3 \cdot 6)\end{array}$ & $\begin{array}{c}246 \\
(4 \cdot 1)\end{array}$ & $\begin{array}{c}2 \cdot 9 \\
(2 \cdot 5-3 \cdot 4)\end{array}$ & $\begin{array}{c}2 \cdot 5 \\
(2 \cdot 1-2 \cdot 9)\end{array}$ & $\begin{array}{c}2 \cdot 8 \\
(2 \cdot 2-3 \cdot 3)\end{array}$ & $\begin{array}{c}2 \cdot 3 \\
(1 \cdot 8-2 \cdot 9)\end{array}$ & $\begin{array}{c}440 \\
(7 \cdot 8)\end{array}$ & $\begin{array}{c}2 \cdot 7 \\
(2 \cdot 4-3 \cdot 0)\end{array}$ & $\begin{array}{c}2 \cdot 2 \\
(2 \cdot 0-2 \cdot 5)\end{array}$ & $\begin{array}{c}4 \cdot 9 \\
(4 \cdot 2- \\
5 \cdot 6)\end{array}$ & $\begin{array}{c}4 \cdot 0 \\
(3 \cdot 2- \\
4 \cdot 7)\end{array}$ \\
\hline $\begin{array}{c}\text { High } \\
\text { Adversity }\end{array}$ & $\begin{array}{c}573 \\
(12 \cdot 3)\end{array}$ & $\begin{array}{c}5 \cdot 5 \\
(5 \cdot 0-6 \cdot 1)\end{array}$ & $\begin{array}{c}3 \cdot 7 \\
(3 \cdot 3-4 \cdot 1)\end{array}$ & $\begin{array}{l}10 \cdot 0 \\
(9 \cdot 0- \\
11 \cdot 0)\end{array}$ & $\begin{array}{c}8 \cdot 3 \\
(7 \cdot 3-9 \cdot 4)\end{array}$ & $\begin{array}{c}212 \\
(8 \cdot 3)\end{array}$ & $\begin{array}{c}5 \cdot 6 \\
(4 \cdot 7-6 \cdot 5)\end{array}$ & $\begin{array}{c}3 \cdot 6 \\
(3 \cdot 1-4 \cdot 3)\end{array}$ & $\begin{array}{c}6 \cdot 8 \\
(5 \cdot 7-7 \cdot 9)\end{array}$ & $\begin{array}{c}5 \cdot 6 \\
(4 \cdot 4-6 \cdot 7)\end{array}$ & $\begin{array}{c}361 \\
(17 \cdot 1)\end{array}$ & $\begin{array}{c}5 \cdot 7 \\
(5 \cdot 0-6 \cdot 4)\end{array}$ & $\begin{array}{c}3 \cdot 7 \\
(3 \cdot 3-4 \cdot 3)\end{array}$ & $\begin{array}{l}14 \cdot 0 \\
(12 \cdot 2- \\
15 \cdot 8) \\
\end{array}$ & $\begin{array}{l}11 \cdot 7 \\
(9 \cdot 9- \\
13 \cdot 5)\end{array}$ \\
\hline
\end{tabular}

Table 2: Post-Traumatic Stress Disorder (PTSD) by childhood adversity trajectory and sex (stratified analyses). DANLIFE, $\mathrm{n}=1277548$, unadjusted and adjusted Cox proportional hazards analyses.

PYRS: Person years

$\mathrm{HR}=$ hazard ratios $(95 \% \mathrm{CI})$; estimated with a Cox model 
$\mathrm{HD}=$ hazards differences $(95 \% \mathrm{CI})$; estimated with an Aalen model

$\mathrm{a}=$ adjusted for parental education at birth, maternal age at birth, mother living with a partner the same year as the individual was born, sex, birth year (80-84,85-89,90-94,95-2001), and parental region of origin. 
Supplementary Table 1: Dimensions and definition of childhood adversities in the DANLIFE study.

\begin{tabular}{cll}
\hline Dimension & Adversity & Registers \\
\hline \multirow{2}{*}{ Material Deprivation } & Family poverty & The Income Statistics Register \\
& Long-term unemployment & The Integrated Database for Labour Market Affiliation \\
& Death of a parent & The Danish Civil Registration System \\
& Death of a sibling & The Danish Civil Registration System \\
& Parental somatic illness & The Danish National Patient Register \\
& Sibling somatic illness & The Danish National Patient Register \\
& Foster care & The Register of Support for Children and Adolescents \\
& Parental psychiatric illness & The Danish Psychiatric Central Research Register; The \\
& Danish National Patient Register \\
& Sibling psychiatric illness & The Danish Psychiatric Central Research Register; The \\
& Danish National Patient Register \\
& The Danish Psychiatric Central Research Register; The \\
& Parental alcohol abuse & Danish National Patient Register; The Danish National \\
& Prescription Registry \\
& The Danish Psychiatric Central Research Register; The \\
& Parental drug abuse & Danish National Patient Register; The Danish National \\
& Prescription Registry \\
& Maternal separation & The Danish Civil Registration System
\end{tabular}




\begin{tabular}{|c|c|c|c|c|c|c|c|c|c|c|c|c|c|c|c|}
\hline & \multicolumn{5}{|c|}{ Overall } & \multicolumn{5}{|c|}{ Men } & \multicolumn{5}{|c|}{ Women } \\
\hline & $\begin{array}{c}\text { Cases (rate } \\
\text { per } 10000 \\
\text { PYRS) }\end{array}$ & $\begin{array}{c}\text { HR } \\
(95 \% \mathrm{CI})\end{array}$ & $\begin{array}{c}\text { aHR } \\
(95 \% \mathrm{CI})\end{array}$ & $\begin{array}{c}\text { HD } \\
\text { [additional } \\
\text { cases per } \\
10000 \\
\text { PYRS] } \\
(95 \% \text { CI })\end{array}$ & $\begin{array}{c}\text { aHD } \\
\text { [additional } \\
\text { cases per } \\
10000 \\
\text { PYRS] } \\
(95 \% \mathrm{CI})\end{array}$ & $\begin{array}{c}\text { Cases } \\
\text { (rate } \\
\text { per } \\
\text { 10000 } \\
\text { PYRS) }\end{array}$ & $\underset{(95 \% \mathrm{CI})}{\text { HR }}$ & $\begin{array}{c}\text { aHR } \\
(95 \% \mathrm{CI})\end{array}$ & $\begin{array}{c}\text { HD } \\
\text { [additional } \\
\text { cases per } \\
10000 \\
\text { PYRS] } \\
(95 \% \mathrm{CI})\end{array}$ & $\begin{array}{c}\text { aHD } \\
\text { [additional } \\
\text { cases per } \\
10000 \\
\text { PYRS] } \\
(95 \% \mathrm{CI})\end{array}$ & 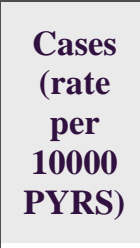 & HR & aHR & $\begin{array}{c}\text { HD } \\
\text { [additional } \\
\text { cases per } \\
10000 \\
\text { PYRS] } \\
(95 \% \text { CI })\end{array}$ & $\begin{array}{c}\text { aHD } \\
\text { [additional } \\
\text { cases per } \\
10000 \\
\text { PYRS] } \\
(95 \% \text { CI })\end{array}$ \\
\hline $\begin{array}{c}\text { Low } \\
\text { Adversity }\end{array}$ & $1524(2 \cdot 2)$ & 1 (ref) & 1 (ref) & 0 (ref) & 0 (ref) & $\begin{array}{c}525 \\
(1 \cdot 4)\end{array}$ & 1 (ref) & 1 (ref) & 0 (ref) & 0 (ref) & $\begin{array}{c}1011 \\
(3)\end{array}$ & 1 (ref) & 1 (ref) & 0 (ref) & 0 (ref) \\
\hline $\begin{array}{c}\text { Early Life } \\
\text { Material } \\
\text { Deprivation }\end{array}$ & $1064(3 \cdot 7)$ & $\begin{array}{c}1 \cdot 7 \\
(1 \cdot 5- \\
1 \cdot 8)\end{array}$ & $\begin{array}{c}1 \cdot 4 \\
(1 \cdot 3- \\
1 \cdot 5)\end{array}$ & $\begin{array}{c}1.4(1.2- \\
1 \cdot 7)\end{array}$ & $\begin{array}{c}0 \cdot 8(0 \cdot 6- \\
1 \cdot 1)\end{array}$ & $\begin{array}{c}364 \\
(2 \cdot 4)\end{array}$ & $\begin{array}{c}1 \cdot 6 \\
(1.4- \\
1.9)\end{array}$ & $\begin{array}{c}1 \cdot 4 \\
(1 \cdot 2- \\
1 \cdot 6)\end{array}$ & $\begin{array}{c}0 \cdot 9(0 \cdot 6- \\
1 \cdot 2)\end{array}$ & $\begin{array}{c}0 \cdot 5(0 \cdot 2- \\
0 \cdot 7)\end{array}$ & $710(5)$ & $\begin{array}{c}1 \cdot 7 \\
(1 \cdot 5- \\
1 \cdot 8)\end{array}$ & $\begin{array}{c}1 \cdot 4 \\
(1 \cdot 3- \\
1 \cdot 6)\end{array}$ & $\begin{array}{c}2 \cdot 0(1 \cdot 6- \\
2 \cdot 4)\end{array}$ & $\begin{array}{c}1 \cdot 2(0 \cdot 8 \\
1 \cdot 6)\end{array}$ \\
\hline $\begin{array}{c}\text { Persistent } \\
\text { Material } \\
\text { Deprivation }\end{array}$ & $1089(5)$ & $\begin{array}{l}2 \cdot 1 \\
(2 \cdot 0- \\
2 \cdot 3)\end{array}$ & $\begin{array}{l}1 \cdot 8 \\
(1 \cdot 7- \\
2 \cdot 0)\end{array}$ & $\begin{array}{c}2 \cdot 5(2 \cdot 2- \\
2 \cdot 8)\end{array}$ & $\begin{array}{c}1 \cdot 9(1 \cdot 5- \\
2 \cdot 2)\end{array}$ & $\begin{array}{c}400 \\
(3 \cdot 5)\end{array}$ & $\begin{array}{c}2 \cdot 2 \\
(1 \cdot 9- \\
2 \cdot 5)\end{array}$ & $\begin{array}{l}1 \cdot 8 \\
(1 \cdot 6- \\
2 \cdot 1)\end{array}$ & $\begin{array}{c}1 \cdot 8(1 \cdot 4- \\
2 \cdot 1)\end{array}$ & $\begin{array}{c}1 \cdot 3(0 \cdot 9- \\
1 \cdot 7)\end{array}$ & $\begin{array}{c}697 \\
(6 \cdot 5)\end{array}$ & $\begin{array}{c}2 \cdot 1 \\
(1 \cdot 9- \\
2 \cdot 3)\end{array}$ & $\begin{array}{c}1 \cdot 8 \\
(1 \cdot 6- \\
2 \cdot 0)\end{array}$ & $\begin{array}{c}3 \cdot 3(2 \cdot 8- \\
3 \cdot 8)\end{array}$ & $\begin{array}{c}2 \cdot 5(2 \cdot 0- \\
3 \cdot 0)\end{array}$ \\
\hline $\begin{array}{c}\text { Loss or } \\
\text { Threat of } \\
\text { Loss }\end{array}$ & $679(5 \cdot 9)$ & $\begin{array}{l}2 \cdot 8 \\
(2 \cdot 5- \\
3 \cdot 0)\end{array}$ & $\begin{array}{l}2 \cdot 3 \\
(2 \cdot 1- \\
2 \cdot 5)\end{array}$ & $\begin{array}{c}3 \cdot 8(3 \cdot 3- \\
4 \cdot 3)\end{array}$ & $\begin{array}{c}3 \cdot 1(2 \cdot 7- \\
3 \cdot 6)\end{array}$ & $\begin{array}{c}246 \\
(4 \cdot 1)\end{array}$ & $\begin{array}{l}2 \cdot 9 \\
(2 \cdot 5- \\
3 \cdot 4)\end{array}$ & $\begin{array}{l}2 \cdot 5 \\
(2 \cdot 1- \\
2 \cdot 9)\end{array}$ & $\begin{array}{c}2 \cdot 8(2 \cdot 2- \\
3 \cdot 3)\end{array}$ & $\begin{array}{c}2 \cdot 3(1 \cdot 8- \\
2 \cdot 9)\end{array}$ & $\begin{array}{l}440 \\
(7 \cdot 8)\end{array}$ & $\begin{array}{c}2 \cdot 7 \\
(2 \cdot 4- \\
3 \cdot 0)\end{array}$ & $\begin{array}{c}2 \cdot 2 \\
(2 \cdot 0- \\
2 \cdot 5)\end{array}$ & $\begin{array}{c}4.9(4 \cdot 2- \\
5 \cdot 6)\end{array}$ & $\begin{array}{c}4 \cdot 0(3 \cdot 2 \\
4 \cdot 7)\end{array}$ \\
\hline $\begin{array}{c}\text { High } \\
\text { Adversity }\end{array}$ & $566(12 \cdot 3)$ & $\begin{array}{c}5 \cdot 5 \\
(5 \cdot 0- \\
6 \cdot 0)\end{array}$ & $\begin{array}{c}3 \cdot 7 \\
(3 \cdot 3- \\
4 \cdot 1)\end{array}$ & $\begin{array}{c}10 \cdot 0(9 \cdot 0- \\
11 \cdot 0)\end{array}$ & $\begin{array}{c}8 \cdot 3(7 \cdot 2- \\
9 \cdot 3)\end{array}$ & $\begin{array}{c}212 \\
(8 \cdot 3)\end{array}$ & $\begin{array}{c}5 \cdot 6 \\
(4 \cdot 7- \\
6 \cdot 5)\end{array}$ & $\begin{array}{c}3 \cdot 6 \\
(3 \cdot 1- \\
4 \cdot 3)\end{array}$ & $\begin{array}{c}6 \cdot 8(5 \cdot 7- \\
7 \cdot 9)\end{array}$ & $\begin{array}{c}5 \cdot 6(4 \cdot 4- \\
6 \cdot 7)\end{array}$ & $\begin{array}{c}361 \\
(17 \cdot 1)\end{array}$ & $\begin{array}{c}5 \cdot 7 \\
(5 \cdot 0- \\
6 \cdot 4)\end{array}$ & $\begin{array}{c}3 \cdot 7 \\
(3 \cdot 3- \\
4 \cdot 3)\end{array}$ & $\begin{array}{c}14 \cdot 0 \\
(12 \cdot 2- \\
15 \cdot 8)\end{array}$ & $\begin{array}{c}11 \cdot 7(9 \cdot 9 \\
13 \cdot 5)\end{array}$ \\
\hline
\end{tabular}

Supplementary table 2: Post-Traumatic Stress Disorder (PTSD) by childhood adversity trajectories and sex (stratified analyses). Results from the adjusted and the unadjusted survival analysis. Adjusted analyses were further adjusted for birth weight.

Final study sample in multivariate analysis including restriction to full information about birth weight $(\mathrm{n}=1264630)$

PYRS: Person years

HR = hazard ratios $(95 \% \mathrm{CI})$; estimated with a Cox model 
$\mathrm{HD}=$ hazards differences $(95 \% \mathrm{CI})$; estimated with an Aalen model

$\mathrm{a}=$ adjusted for parental education at birth, maternal age at birth, mother living with a partner the same year as the individual was born, sex, birth year (80-84,85-89,90-94,95-2001), parental region of origin, and birth weight. 